\title{
Neonatal Mortality and Maternal/Child Health Care in Nigeria: An Impact Analysis
}

\section{EWERE, F; EKE, DO}

\author{
Department of Statistics, University of Benin, Benin City, Nigeria \\ *Corresponding Author Email: friday.ewere@uniben.edu
}

\begin{abstract}
Reducing the rate of mortality in neonates to as low as 12 per 1,000 live births is one of the clearly spelt out aims of the third tenet of the Sustainable Development Goals (SDG) because of its importance to the dynamics of population. While there have been various studies focused majorly on the causes, rates and determinants of neonatal mortality in Nigeria, studies on the impact of maternal/child care characteristics on neonatal mortality and the potential implication of failing to attain the SDG target for neonatal mortality have seemingly been neglected. In this study, we undertake an analysis of the impact of maternal / child care characteristics on neonatal mortality using the logistic regression model. Results from the study showed that antenatal care $(P$-value $=0.000$, odds ratio $=0.546$ for women who visited the hospital during pregnancy on more than 5 occasions), post natal care ( $P$-value $=0.004$, odds ratio $=0.402$ for women who received early neonatal care from skilled medical personnel), place of delivery $(P$-value $=0.000$, odds ratio $=0.592$ for babies that were delivered in a government hospital $)$ and skill of birth attendant $(P$-value $=0.000$, odds ratio $=0.706$ for babies who were delivered by trained doctors/nurses/midwives) had significant impact on neonatal mortality at the $95 \%$ confidence level implying that improved maternal health care: before, during and immediately after delivery as well as the quality of care to mother and child are both important and necessary to the reduction of neonatal mortality in Nigeria. To achieve the sustainable development target for neonatal mortality, it is therefore recommended that stake holders in the public health sector improve the quality of existing health care facilities and access to quality services.
\end{abstract}

\section{DOI: https://dx.doi.org/10.4314/jasem.v24i7.26}

Copyright: Copyright (C) 2020 Ewere and Eke. This is an open access article distributed under the Creative Commons Attribution License (CCL), which permits unrestricted use, distribution, and reproduction in any medium, provided the original work is properly cited.

Dates: Received: 16 May 2020; Revised: 29 June 2020; Accepted: 07 July 2020

Keywords: Neonatal mortality, logistic regression, maternal care, child health care, Nigeria

Neonatal mortality which is the absence of all traces of life in a live birth between birth and the first 28 days of life (World Health Organization (WHO), 2011) is one of the glaring targets of the Sustainable Development Goals (SDG) because of its importance to the dynamics of any population and the role that it plays as a barometer for the measurement of social economic and demographic development (Hall, 2005). Although there have been significant progress globally in the fight against childhood mortality, neonatal mortality still maintained significantly high rates with neonatal mortality contributing nearly $50 \%$ of all mortality in children under the age of five globally and about two thirds of infant mortality (Akinyemi et al., 2015). In 2018, 5.3 million children died before their fifth birthday with a staggering 2.5 million of those childhood death $(47 \%)$ occurring in the first month of life (United Nations Inter-agency Group for Childhood Mortality Estimation (UN-IGME), 2019). Whist the 2.5 million deaths of neonates globally represents progress relative to the number of neonatal mortality in 1990 which was about 5 million babies, efforts to further reduce its occurrence and accelerate progress in preventing child deaths should be considered urgent and intensified as an alarming 7000 neonates still die daily of preventable causes/illness as recently as 2018. (National Population Commission (NPC), 2018). On current trends, over 24 million babies will die in the first month of their lives between 2019 and 2030 which is approximately 2.2 million preventable annual neonatal deaths (UN-IGME, 2019). Most of these neonatal deaths occur in low and middle income countries with the highest number of occurrence recorded in south-central Asian countries and the highest rates generally in sub-Saharan Africa. (UNICEF, 2018). In Nigeria, it is unbelievably sad to know that the number of neonates that still die of preventable/treatable causes and diseases as at the year 2020 is as high as 38 per 1,000 live births (UN-IGME, 2019). The feeling that we have repeated failed the next generation and the new born is made even truer by the fact that there have not been any substantial changes in neonatal mortality in the last decade (40 deaths per 1,000 live births in 2008 versus 39 deaths per 1,000 live births in 2018) (National Population Commission (NPC), 2018; National Bureau of Statistics (NBS), 2018). This alarmingly high frequency with which new born babies die do not only

*Corresponding Author Email: friday.ewere@uniben.edu 
put the country at risk of failing to achieve the sustainable development target of childhood mortality, it can also spell serious consequences for the future of our beloved nation (Ewere and Eke, 2020; Eke and Ewere 2020). It is therefore both important and imperative that researchers monitor the progress of this target in Nigeria.

According to Lancet (2018), three quarters of neonatal deaths usually occurs in the first week of life with the first day of birth representing the highest risk of neonatal death. Most of these newborns death are caused by preterm birth, severe infections, asphyxia, maternal complications in labour and birth injuries resulting from poorly managed labour and lack of emergency obstetrics service and can be prevented by reaching high coverage of quality antenatal care, skilled care at birth, postnatal care for mother and baby, and care of small and sick newborns. (Hall, 2005; Titaley et al., 2012). Given the possible impact that neonatal mortality could potentially have on population dynamics, life expectancy and under-five mortality rates as well as on the mothers of the deceased babies, there is need for studies that focuses on the link between maternal/child health care during and after pregnancy and neonatal mortality. However, studies on neonatal mortality have seemingly suffered neglect in favour of under-five mortality. Most indigenous researchers in the field of child survival studies who have carried out researches in neonatal mortality have often tended to focus on health facilitybased regional mortality rates and trends using data obtained from tertiary health facilities subject to selection bias (Bamgboye and Familusi, (1990); Njokanma, (1995); Adimora and Odetunde, (2007); Udo, (2008); Omoigberale et al., (2010); Adedini, (2014)). Others who have used national representative survey have tended to focus on the determinant and trends of neonatal mortality (Akinyemi et al., (2015); Usman et al., (2019)). Therefore, the objective of this paper is to report the study on the impact of maternal / child care characteristics on neonatal mortality using the logistic regression model.

\section{MATERIAL AND METHOD}

Study Area: This paper is focused on Nigeria. Nigeria which is the most populous country in Africa is divided into 36 states and a Federal Capital Territory (FCT), grouped into six geopolitical zones; North Central, North-East, North-West, South-East, SouthSouth, and South-West.

Data Source: The study utilized data obtained from the Nigeria Demographic and Health Survey (NDHS) for 2018 for its analysis. The survey used a two stage cluster design for the selection of its respondent and collected primary information about households including sexual and reproductive health histories from women between the ages of 15 and 49 for the five years preceding 2018. For the purpose of this study, the child recode data which contains all follow-up information on all children born to the interviewed women within five years preceding the survey is used.

\section{Variables}

Outcome variables: The outcome variable for this study is neonatal mortality. The dataset was cleaned and the age at death variable imputed in days, weeks and months was recoded and used to obtain all deaths within the neonatal period (first month of life) for all children born to the interviewed women.

The Explanatory variables: The explanatory (independent) variables included in this study based on the objective of the study are:

Mode of delivery $=\mathrm{MoD}$; Care at Birth $=\mathrm{CaB}$; Post Natal Care $=$ PnC; Number of Antenatal Visit $=\mathrm{NaV}$; Size of child at birth $=\mathrm{ScB}$; Caesarean Section Decision Timing $=$ CsDT and Place of Delivery $=$ PoD. Data cleaning, manipulation and analysis were performed using SPSS software version 22.

Statistical Analysis: In the 2018 NDHS survey, 41,821 women participated and 33,924 children were born to the women within five years preceding the survey. Of the 33,924 children born to the interviewed mothers, 1,278 children died within the first 28 days of life (neonatal period). All analysis in this study was based on the survivorship of the 33,924 children within the first month of their lives. The analysis of the study based on the selected maternal/ child health care characteristics, was conducted in three stages. First, the univariate analysis was conducted to obtain information on the background characteristics of the women in Nigeria relative to the appropriate explanatory variables and the summary of the frequency distribution displayed in Tables 1-7. Next, the bivariate relationship between maternal/childhealth care characteristics and neonatal mortality was obtained using the chi-square test of association to determine the significant bivariate correlation between the risk factors of the selected maternal/child-health care characteristics and the outcome variable (neonatal mortality). Subsequently an analysis of the estimates of neonatal mortality rate by the selected mother's health/childcare related characteristics in Nigeria were obtained. The third stage of the study's statistical analysis was conducted to determine the extent to which all the variables had an impact on neonatal mortality in Nigeria dependent on each other's presence using the binary logistic regression model. 
The logistic regression test performed using the SPSS software at $5 \%$ significance level reports the odds ratio, confidence interval and statistical significance $(P$-value $)$ which broadened insights on the impact of mother and child health care during and immediately after delivery on neonatal mortality in Nigeria.

The single variable logistic regression model is given by:

$$
f(x)=\frac{\exp \beta_{0}+\beta_{1}}{1+\exp \beta_{0}+\beta_{1}}
$$

The transformation of $f(x)$ that is central to the study of logistic regression is the logit transformation. This transformation is defined in terms of $f(x)$ as

$$
\lambda=\beta_{0}+\beta_{1}
$$

The multiple logistic regression model is given by:

$$
P(Y=1 \mid X)=f(x)=\frac{\exp \left(\beta_{0}+\beta_{1} X_{1}+\beta_{2} X_{2}+\cdots+\beta_{n} X_{n}+\mu\right)}{1+\exp \left(\beta_{0}+\beta_{1} X_{1}+\beta_{2} X_{2}+\cdots+\beta_{n} X_{n}+\mu\right)}
$$

Where $\mathrm{n}$ is the number of independent variables. The logit transformation for the multiple logistic regression is given by:

$$
\lambda=\beta_{0}+\beta_{1} X_{1}+\beta_{2} X_{2}+\cdots+\beta_{n} X_{n}+\mu
$$

Thus, the regression model is given by

$$
\begin{gathered}
f(x)=\frac{e^{\lambda}}{1+e^{\lambda}} \ldots \ldots \ldots(5) \quad \begin{array}{l}
\text { The logit of the logistic regression mo } \\
\text { significant effect of maternal/child care } \\
\text { on the outcome variable (neonatal mortal } \\
\text { study is given as }
\end{array} \\
\lambda=\beta_{0}+\beta_{1} M o D+\beta_{2} C a B+\beta_{3} P n C+\beta_{4} N a V+\beta_{5} S c B+\beta_{6} C S D T+\beta_{7} P o D+\mu \ldots
\end{gathered}
$$

The odds ratio of neonatal mortality which is the relative risk of the occurrence of neonatal mortality is a measure of the probability of success $P(y=1)$ to the probability of failure $1-\mathrm{P}(\mathrm{y}=0)$ and is given by

$$
\frac{p}{1-p}
$$

The logit of the logistic regression model to test the significant effect of maternal/child care characteristics on the outcome variable (neonatal mortality) for this

and the logistic regression model is given as

$$
\begin{gathered}
Y_{\text {neo }}=\frac{\exp \left(\beta_{0}+\beta_{1} M o D+\beta_{2} C a B+\beta_{3} P n C+\beta_{4} N a V+\beta_{5} S c B+\beta_{6} C s D T+\beta_{7} P o D+\mu\right)}{1+\exp \left(\beta_{0}+\beta_{1} M o D+\beta_{2} C a B+\beta_{3} P n C+\beta_{4} N a V+\beta_{5} S c B+\beta_{6} C s D T+\beta_{7} P o D+\mu\right)} \\
y_{\text {neo }}= \begin{cases}1 & \text { child died as a neonate } \\
0 & \text { child is alive }\end{cases}
\end{gathered}
$$

where $y$ is the outcome variable and it is referred to as the logistic transformation of probability of neonatal mortality occurring. $\beta_{0}$ is the intercept representing the probability of occurrence of the neonatal mortality in the absence of all the underlying factors. $\beta_{1}, \ldots, \beta_{7}$ are the odds ratios of neonatal mortality occurring. The $" \mu$ " is the error term.

\section{RESULTS AND DISCUSSION}

Table 1 shows the frequency distribution of the 'mode of delivery' determinant of neonatal mortality. A total of 33,778 children born to the interviewed women representing $99.6 \%$ of the children born to the interviewed women within the five years preceding the NDHS 2018 were reported. This differs from the 33,924 of the children born to the interviewed women. This difference could be as a result of missing values or non-response from the interviewed mothers. From Table 1, 97.0\% of the women delivered their babies normally while $2.6 \%$ of the interviewed mothers gave birth to their babies via a Caesarean Section. Table 2 displays the frequency distribution of the number of antenatal visits by the interviewed mothers prior to the delivery of their babies for the five years preceding the 2018 NDHS. Table 2 reveals that more than half of the women interviewed did not visit the hospital for antenatal care before the delivery of their babies. This could be as a result of the fact that most of the women interviewed were from rural communities who did not have ready access to hospitals, clinics and government owned health centres. Only $21.4 \%$ of the interviewed mothers visited the hospital on five or more occasions. The frequency distribution of the sizes at birth of children born to the interviewed women for the five years preceding the 2018 survey is shown in Table 3. Over half of the children given birth to were average sized babies with only about $14 \%$ of the babies recorded to be small sized babies. The size of the baby could also potentially determine the weight at birth. 
Table 4 is a display of the frequency distribution of the timing on the decision for giving birth via a CS. A total of 879 children were reported to have been given birth to via CS. This represents $2.6 \%$ of the total number of children given birth to in the five years preceding the NDHS for 2018.

Table 1. Frequency distribution of live births by the mode of

\begin{tabular}{lcc}
\multicolumn{3}{c}{ delivery } \\
\hline Variable & Frequency & Percentage \\
\hline Mode of Delivery & & \\
Normal Delivery & 32899 & 97.0 \\
Caesarean Section & 879 & 2.6 \\
Total & 33778 & 99.6 \\
\hline
\end{tabular}

Table 2: Frequency distribution of the number of antenatal visit

\begin{tabular}{lll}
\hline Variable & Frequency & Percentage \\
\hline $\begin{array}{l}\text { Number of Antenatal } \\
\text { Visit }\end{array}$ & & \\
None & 17824 & 52.5 \\
Below 5 & 8853 & 26.1 \\
5 and above & 7247 & 21.4 \\
Total & 33924 & 100.0 \\
\hline
\end{tabular}

Table 3: Frequency distribution of size of child at birth

\begin{tabular}{lll}
\hline Variable & Frequency & Percentage \\
\hline Size of child at birth & & \\
Large & 11275 & 33.2 \\
Average & 17551 & 51.7 \\
Small & 4572 & 13.5 \\
Total & 33398 & 98.4 \\
\hline
\end{tabular}

The decision of timing is an important determinant of neonatal mortality and is closely related to antenatal visits. Mothers who frequently made the antenatal care trip to the hospital were more likely to know if they could give birth normally or would require a CS. From the total of 879 babies delivered via CS, 499 babies representing $56.77 \%$ were given birth to after their mothers had entered into labour only to discover that they could not give birth normally. The frequency distribution of the place of delivery as a maternal health care determinant of neonatal mortality is displayed in Table 5. From the table, 19,949 babies were given birth to at home accounting for approximately $59 \%$ of the total number of babies born to the interviewed mothers for the 2018 NDHS. Government owned health centers accounted for most of the babies given birth to in the hospital with only $12.2 \%$ given birth to in private hospitals. Table 6 displays the frequency distribution of the personnel that took charge of the delivery and care of the babies born to the interviewed mothers in the five years preceding the survey. The total of 7,328 which represents $21.6 \%$ of the total number of babies born for the five years preceding the interview is the number of babies whose health were checked before discharge. Of the number of babies whose health were checked before discharge, 6,947 babies representing
$94.8 \%$ received care at birth by trained medical personnel with only 29 babies representing $0.4 \%$ being attended to by traditional birth attendants.

Table 4: Frequency distribution of caesarean section decision timing

\begin{tabular}{lll}
\hline Variable & Frequency Percentage \\
\hline Caesarean Section Decision Timing & & \\
Before Labour Started & 380 & 43.23 \\
After Labour Started & 499 & 56.77 \\
Total & 879 & 100.00 \\
\hline
\end{tabular}

Table 5: Frequency distribution of place of delivery

\begin{tabular}{lll}
\hline Variable & Frequency & Percentage \\
\hline Place of Delivery & & \\
Home & 19949 & 58.8 \\
Public/Government Hospital & 9365 & 27.6 \\
Private Hospital & 4123 & 12.2 \\
Total & 33437 & 98.6 \\
\hline
\end{tabular}

Table 6: Frequency distribution of 'care at delivery'

\begin{tabular}{lll}
\hline Variable & Frequency & Percentage \\
\hline Care at Birth & & \\
Trained Doctors / Nurses / & 6947 & 94.8 \\
$\begin{array}{l}\text { Midwives } \\
\text { Auxiliary Nurses / Community }\end{array}$ & 352 & 4.8 \\
Health Workers & 29 & 0.4 \\
Traditional Birth Attendant & 7328 & 100.0 \\
Total & & \\
\hline
\end{tabular}

Table 7: Frequency distribution of 'post natal care'

\begin{tabular}{lll}
\hline Variable & Frequency & Percentage \\
\hline Post Natal Care & & \\
Skilled & 3365 & 74.3 \\
Semi-skilled & 355 & 7.8 \\
Unskilled & 811 & 17.9 \\
Total & 4531 & 100.0 \\
\hline
\end{tabular}

Table 7 displays the frequency distribution of post natal care for the babies given birth to for the five years preceding the 2018 NDHS. Of the 33,924 babies, only 4,531 accounting for a paltry $13.4 \%$ were given post natal care. This relatively low number of babies receiving post natal care relative to the number of babies born to the interviewed number partly explains the averagely high number of neonatal mortality in Nigeria. From Table 7, a total of 3,365 babies representing $74.3 \%$ received postnatal care from skilled personnel. Table 8 is a summary of the results of cross tabulation analysis carried out between the selected maternal/child care characteristics and neonatal mortality using Pearson chi-square test of association. Table 8 shows that there exists a strong bivariate relationship between each of the selected maternal/child care characteristics and neonatal mortality with each independent variable having $P$ value $<0.05$. The percentage of the number of babies that died within the first 28 days of life based on the "care at birth" variable were $2.1 \%, 2.3 \%$ and $0 \%$ for the deliveries that were carried out by- trained 
doctors/nurses, auxiliary nurses and traditional birth attendants respectively. A possible explanation for the $0 \%$ neonatal mortality by traditional birth attendants could be that most of victims of inexperienced traditional birth attendants were not captured in the course of the survey. However, most women who patronize the services of traditional care attendants usually fall into the category of those who may never have visited the hospital for antenatal care and as a result may never know of any underlying health challenge that could lead to complications during child delivery. The 'mode of delivery' as an independent variable also showed significant bivariate relationship with neonatal mortality $(P$-value $=0.000)$ with an associated $3.8 \%$ and $7.3 \%$ mortality rate for babies who were delivered normally and via CS respectively. The number of antenatal visits by pregnant and expectant mother prior to the delivery of their babies is a maternal care characteristic that also showed significant bivariate relationship with neonatal mortality. It was also a factor that could possibly influence the timing of the decision to undergo caesarean section with both variables having an associated $P$-value of 0.000 and 0.029 respectively indicating a significant bivariate association. Table 9 displays the estimates of neonatal mortality rates in Nigeria for the five years preceding the 2018 survey and their confidence intervals based on the selected maternal/child care characteristics. From Table 9, neonatal mortality rates were significantly lower for babies that were given birth to normally with about $92 \%$ neonatal mortality increase for babies who were delivered via caesarean section. A possible reason for the substantial neonatal mortality increase could be due to the fact that a greater number of respondents made the decision to deliver their babies via caesarean section after they had gone into labour allowing little or no time for the delivery care attendant, doctors, nurses or midwife to carry out all the necessary CS procedures. This late $\mathrm{CS}$ decision timing which is closely related to the number of visits during antenatal resulted in about $34 \%$ increase in neonatal mortality relative to mothers who took the decision of a CS before entering into labour. Mothers who visited the hospital during pregnancy for antenatal on 5 or more occasions experienced $50 \%$ less neonatal mortality rates compared to mothers who did not go for any antenatal care prior to the delivery of their babies. Given the fact that most neonatal death occurs in the first week of life, with the first day being the most vulnerable, it therefore comes as no surprise that babies who were given Early Neonatal Care (ENC) by skilled attendants experienced $60 \%$ less neonatal mortality compared to babies who received post natal care from unskilled attendants. The neonatal mortality estimate for the size of the child at birth shows that babies who were small at birth experienced about $50 \%$ more neonatal mortality compared to those babies who were large in size.

\begin{tabular}{|c|c|c|c|}
\hline \multirow[t]{2}{*}{ Maternal/Child care characteristics } & \multicolumn{2}{|c|}{ Neonatal Mortality } & \multirow{2}{*}{$\begin{array}{c}P- \\
\text { value }\end{array}$} \\
\hline & Yes & No & \\
\hline \multicolumn{4}{|l|}{ Care at Birth } \\
\hline Trained Doctors / Nurses / Midwives & 143 & 6803 & \\
\hline Auxiliary Nurses / Community Health Workers & 8 & 344 & 0.022 \\
\hline Traditional Birth Attendant & 0 & 29 & \\
\hline \multicolumn{4}{|l|}{ Mode of Child Delivery } \\
\hline Normal Delivery & 1216 & 31683 & \\
\hline \multirow{2}{*}{\multicolumn{4}{|c|}{ Post Natal Care }} \\
\hline & & & \\
\hline Skilled & 27 & 3337 & \\
\hline Semi-skilled & 4 & 351 & \\
\hline Unskilled & 16 & 795 & 0.000 \\
\hline \multicolumn{4}{|l|}{ Number of Antenatal Visit } \\
\hline None & 855 & 16969 & \\
\hline Below 5 & 229 & 8624 & \\
\hline 5 and above & 194 & 7052 & 0.000 \\
\hline \multicolumn{4}{|l|}{ Size of child at birth } \\
\hline Large & 376 & 10899 & \\
\hline Average & 547 & 17003 & \\
\hline Small & 296 & 4276 & 0.000 \\
\hline \multicolumn{4}{|l|}{ Caesarean Section Decision Timing } \\
\hline Before Labour Started & 22 & 357 & \\
\hline \multicolumn{3}{|l|}{ Place of Delivery } & 0.029 \\
\hline Home & 723 & 19226 & \\
\hline Public/Government Hospital & 369 & 8995 & \\
\hline Private Hospital & 160 & 3963 & 0.036 \\
\hline
\end{tabular}

EWERE, $F$; EKE, DO 
Table 9: Neonatal mortality rate estimates by the selected mother's health/childcare related characteristics in Nigeria

\begin{tabular}{|c|c|c|c|}
\hline \multirow[t]{2}{*}{ Maternal/Child care characteristics } & \multicolumn{2}{|c|}{ Neonatal Mortality } & \multirow{2}{*}{$\begin{array}{c}P- \\
\text { value }\end{array}$} \\
\hline & Yes & No & \\
\hline \multicolumn{4}{|l|}{ Care at Birth } \\
\hline Trained Doctors / Nurses / Midwives & 143 & 6803 & \\
\hline Auxiliary Nurses / Community Health Workers & 8 & 344 & 0.022 \\
\hline Traditional Birth Attendant & 0 & 29 & \\
\hline \multicolumn{4}{|l|}{ Mode of Child Delivery } \\
\hline Normal Delivery & 1216 & 31683 & \\
\hline Caesarean Section & 60 & 818 & 0.000 \\
\hline \multicolumn{4}{|l|}{ Post Natal Care } \\
\hline Skilled & 27 & 3337 & \\
\hline Semi-skilled & 4 & 351 & \\
\hline Unskilled & 16 & 795 & 0.000 \\
\hline \multicolumn{4}{|l|}{ Number of Antenatal Visit } \\
\hline None & 855 & 16969 & \\
\hline Below 5 & 229 & 8624 & \\
\hline 5 and above & 194 & 7052 & 0.000 \\
\hline \multicolumn{4}{|l|}{ Size of child at birth } \\
\hline Large & 376 & 10899 & \\
\hline Average & 547 & 17003 & \\
\hline Small & 296 & 4276 & 0.000 \\
\hline \multicolumn{4}{|l|}{ Caesarean Section Decision Timing } \\
\hline Before Labour Started & 22 & 357 & \\
\hline \multicolumn{3}{|l|}{ Place of Delivery } & 0.029 \\
\hline Home & 723 & 19226 & \\
\hline Public/Government Hospital & 369 & 8995 & \\
\hline Private Hospital & 160 & 3963 & 0.036 \\
\hline
\end{tabular}

Table 10: Impact of the Selected Maternal Health/Child Care Characteristics on Neonatal Mortality in Nigeria

\begin{tabular}{|c|c|c|c|c|}
\hline \multirow[t]{2}{*}{ Variables } & \multirow{2}{*}{$\begin{array}{l}\text { Odds } \\
\text { ratio }\end{array}$} & \multicolumn{2}{|c|}{$95 \%$ Confidence Interval } & \multirow[t]{2}{*}{ P-value } \\
\hline & & Lower & Upper & \\
\hline \multicolumn{5}{|l|}{ Caesarean Section Decision Timing } \\
\hline Before Labour Started DC & 1.000 & & & \\
\hline \multirow{2}{*}{\multicolumn{5}{|c|}{ Size of child at birth }} \\
\hline & & & & \\
\hline Large ${ }^{R C}$ & 1.000 & & & \\
\hline Average & 1.072 & 0.938 & 1.225 & 0.605 \\
\hline Small & 0.498 & 0.426 & 0.583 & 0.530 \\
\hline \multicolumn{5}{|l|}{ Number of Antenatal Visit } \\
\hline None ${ }^{R C}$ & 1.000 & & & \\
\hline Below 5 & 0.832 & 0.563 & 1.146 & 0.000 \\
\hline 5 and above & 0.546 & 0.466 & 0.640 & 0.000 \\
\hline \multicolumn{5}{|l|}{ Mode of Child Delivery } \\
\hline Caegarean Section ${ }^{\mathrm{CC}}$ & 1.000 & & & \\
\hline Normal Delivery & 0.523 & 0.400 & 0.684 & 0.000 \\
\hline \multicolumn{5}{|l|}{ Post Natal Care } \\
\hline Unskilled $\mathrm{RC}$ & 1.000 & & & \\
\hline Semi-skilled & 0.710 & 0.247 & 2.041 & 0.245 \\
\hline Skilled & 0.402 & 0.216 & 0.750 & 0.004 \\
\hline \multicolumn{5}{|l|}{ Place of Delivery } \\
\hline Home ${ }^{R C}$ & 1.000 & & & \\
\hline Public/Government Hospital & 0.592 & 0.489 & 0.642 & 0.000 \\
\hline Private Hospital & 0.377 & 0.267 & 0.451 & 0.000 \\
\hline \multicolumn{5}{|l|}{ Care at Birth } \\
\hline Traditional Birth Attendant ${ }^{\text {DC }}$ & 1.000 & & & \\
\hline Auxiliary Nurses / Community Health Workers & 0.846 & 0.633 & 0.963 & 0.023 \\
\hline Trained Doctors / Nurses / Midwives & 0.706 & 0.540 & 0.811 & 0.000 \\
\hline
\end{tabular}

RC: Reference Category

The place of delivery and care at birth showed only marginal difference in neonatal mortality rates with 41, 38 and 40 as estimates for babies who were delivered at home, public hospitals and private hospitals respectively. The neonatal mortality estimates of 21, 23 and 25 are for babies who received care at birth from trained health care personnels, auxiliary nurses/community health workers and Traditional birth attendants respectively. All the neonatal mortality estimates were calculated at $95 \%$ 
confidence interval. Table 10 presents the results of the logistic regression model used to determine the impact of maternal/child care characteristics on neonatal mortality for the five years preceding the NDHS for 2018. The odds ratio is the exponential of the parameter estimates from the model and it defines the chances of the occurrence of neonatal mortality with respect to each of the reference category for the selected maternal/child care characteristics. The $95 \%$ Confidence Interval (CI) for the odds ratio and the associated $P$-value which is a measure of the degree of statistical significance of the odds ratio are presented. From Table 10, the decision to undergo a caesarean section after the pregnant woman had gone into labour increased the chances of neonatal mortality by about $34 \%$ compared to mothers who made similar decision before they entered into labour with a $P$-value of 0.029 indicating statistical significance. The number of antenatal visits also had significant impact on neonatal mortality. As the number of antenatal visits increased, the likelihood of the occurrence of neonatal death after a live birth reduced with mothers who visited the hospital during pregnancy on five or more occasions having about $45 \%$ less chances of experiencing neonatal mortality with a $P$-value of 0.000 showing statistical significance. The mode of child delivery as a component of child health care characteristics was found to be a statistically significant predictor of neonatal mortality with a $P$-value of 0.000 . As an indirect consequence of the number of times a woman visited the hospital during antenatal, children who were given birth to normally experience reduced neonatal mortality odds of 0.523 indicating about $48 \%$ decrease in neonatal mortality relative to children who were delivered via a CS. Considering the quality of post natal care received by mother and babies immediately after delivery, it was discovered that ENC by skilled health care personnel increased the chances of survival of neonates by about $60 \%$ compared to babies who received ENC from unskilled care givers and attendants. Post natal care by skilled medical personnel was found to have a significant impact on neonatal mortality with an associated $P$ value of 0.004 indicating strong statistical significance. The place of delivering is an important determinant in the survival of neonates with babies born in hospitals with better facilities and health care personnel standing a better chance of survival beyond the first 28 days of life. This is clearly illustrated from Table 10 with reduced neonatal odds of 0.377 and 0.592 for babies born in private and government hospitals respectively indicating that babies delivered in the hospital had a significant impact on neonatal mortality with a $P$-value of 0.000 . On the care at birth variable, being delivered of a new born baby by an auxiliary nurse or community health worker (semi skilled) reduced the odds of neonatal mortality by about $15 \%$ relative to being attended to during delivering by traditional practitioners with a $P$-value of 0.023 . Being attended to by trained doctors/nurses/midwives further reduced the odds of neonatal mortality by about $30 \%$ with a $P$-value of 0.000 indicating statistical significance. The size of the baby at birth was found not to be a statistically significant determinant of neonatal mortality with $P$ value $>0.005$.

Conclusion: This study applied the logistic regression model to examine the impact of maternal /child care characteristics on neonatal mortality in Nigeria. Findings from this study revealed that antenatal care, place of delivery, mode of delivery and the skill of birth attendants were statistically significant determinants of neonatal mortality implying that improved maternal health care before, during and immediately after delivery is essential to the reduction of the seemingly static neonatal mortality rates in Nigeria.

Acknowledgment: The authors would like to thank the National Population Commission, Abuja, Nigeria and all the other partners who were involved in the NDHS for 2018. We are also grateful to the National Population Commission and ICF Macro Calverton, Maryland, USA for access to the data used for this study.

\section{REFERENCES}

Adedini, SA; Odimegwu, C; Bamiwuye, O; Fadeyibi, O; De Wet, N (2014). Barriers to accessing health care in Nigeria: Implications for child survival. Global health action. 7: 234-99

Adimora, GN; Odetunde, IO (2007). Perinatal mortality in University of Nigeria Teaching Hospital (UNTH) Enugu at the end of the last millennium. Niger. J. Clin Pract. 10: 19-23

Akinyemi, JO; Bamgboye, EA; Ayeni, O (2015). Trends in neonatal mortality in Nigeria and effects of bio-demographic and maternal characteristics. BMC pediatrics, 15,36

Bamgboye, EA; Familusi, JB (1990) Mortality pattern at a children's emergency ward, University College Hospital, Ibadan, Nigeria. Afr. J. of med. Sci. 19(2): 127-132

Eke, DO; Ewere, F (2020). Modeling and Forecasting Under-Five Mortality Rate in Nigeria using AutoRegressive Integrated Moving Average Approach. Earthline J. of Mathematical Sci. 4(2): 
347-360

https://doi.org/10.34198/ejms.4220.347360

Ewere, F; Eke, DO (2020). Time Series Analysis and Forecast of Infant Mortality Rate in Nigeria: An ARIMA Modeling Approach. Canadian J. of Pure and Appl. Sci.14 (2): 5049-5059.

Hall, S (2005). Neonatal mortality in developing countries: what can we learn from DHS data? Application and policy working paper A05/02. Southampton: University of Southampton.

Lancet, (2018). National, regional and global levels and trends in neonatal mortality between 1990 and 2017, with scenario-based projections to 2030: a systematic analysis.7(6): 710-720.

Njokanma, OF; Olarenwaju DM (1995). A study of neonatal deaths at the Ogun State University Teaching Hospital, Sagamu, Nig. J. Trop. Med. Hyg. 98: 155-160

National Bureau of Statistics (NBS) and United Nations Children's Fund (UNICEF). 2017 Multiple Indicator Cluster Survey (MICS) 2016 17, Survey Findings Report. Abuja, Nigeria: National Bureau of Statistics and United Nations Children's Fund.

National Population Commission (NPC) [Nigeria] and ICF.2019. 2018 Nigerian DHS Key Findings. Abuja, Nigeria and Rockville, Maryland, USA: NPC and ICF.

Omoigberale, AI; Sadoh, WE; Nwaneeri, DU (2010). A 4 year review of neonatal outcome at the
University of Benin Teaching Hospital, Benin City. Nig. J. of clin. Pract. 13(3): 321-325.

Titaley, CT; Dibley, MJ; Roberts CL (2012). Type of delivery attendant, place of delivery and risk of early neonatal mortality: analyses of the 19942007 Indonesian Demographic and Health Surveys. Health Policy and Plan. 27: 405- 416

Udo, JJ; Anah, MU; Ochigbo, SO; Etuk, IS; Ekanem, AD (2008). Neonatal morbidity and mortality in Calabar, Nigeria: A hospital-based study. Nig. J. of clin. Pract. 11(3): 285-289.

UNICEF, (2018). Levels and Trends in Child Mortality: Report 2018. Estimates Developed by the UN Inter-agency Group for Child Mortality Estimation.

UN-IGME (2019). Levels and Trends in Child Mortality. Report 2019. Estimates developed by the UN inter-agency Group for Child Mortality Estimation. United Nations Children's Fund. New York.

Usman, A; Sulaiman, MA; Abubakar, I (2019). Trends of Neonatal Mortality in Nigeria from 1990 to 2017 using Time Series Analysis. J. Appl. Sci. Environ. Manage. 23(5): 865-869 https://www.ajol.info/index.php/jasem

World Health Organisation, WHO (2011). Child Mortality: Millennium Development Goal (MDG) 4. The Partner for Maternal and New Born Birth, World Health Organisation. September, 2011.

http://www.who.int/pmnch/media/press_material s/fs/fs mdg4 childmortality/en/. 